\title{
Dynamical control of dimensional quality of large steel structures in production enterprises of low - level technological support
}

\author{
Radosław Rutkowski, Ph. D. \\ West Pomeranian University of Technology, Szczecin
}

\section{ABSTRACT}

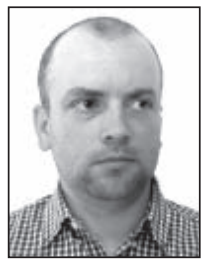

In this paper problems of dimensional control in the building process of large steel structures are discussed. Results are presented of the research aimed at the improving of dimensional quality of prefabricated ship hull structures built in enterprises of medium-or low-level technological support. Problems of dimensional control in building process of large steel structures are highlighted. A solution is proposed of dynamical control of measurement operations as well as their optimization with taking into account current production process parameters. An example of calculations carried out in the frame of the presented solution is also attached.

Keywords: shipbuilding metrology, technology, large steel structures, shipbuilding, dimensional quality, mathematical modelling.

\section{INTRODUCTION}

As dimensional quality problems are not very much spread in shipbuilding circles, basic introductory information on the issue is presented below.

The main task of a shipyard is obviously to produce ships of the highest quality at the possibly lowest cost, i.e. arising from economical consumption of materials and the possible shortest production cycle. Moreover reaching the economic success depends on keeping the assumed contractual parameters such as a.o. ship' s length, depth, breadth, minimum keel plate deformations, and finally- ship' s speed, deadweight and fuel consumption etc. The reasons lead to very high quality requirements in the sense of design of technological processes and rationalization of processes of manufacturing and production quality control. Ship hull is assembled of many structural elements. Nowadays built ships are often consisted of more than a hundred sections. In Fig. 1 an example sectional division is presented. In order to make correct matching and joining the hull elements possible it is necessary to keep their dimensions, shapes and mutual position in compliance with design of the ship. In realizing the aim measurement control operations serve as main tools applied at every building phase beginning from lofting through cutting, bending, up to final assembling the ship hull after launching.They make it possible to check compliance of design of a given structure with its realization during production cycle up to its endThe problems are covered by shipbuilding metrology.

Dimensional quality problems of small-size (up to 500 $\mathrm{mm}$ ) and medium-size objects (up to $1150 \mathrm{~mm}$ ), which concern both technological processes and means of production are fully mastered. For manufacturing such objects the GPS system (Geometry Product Specification) containing methods of dimensioning, dimensional tolerancing and fitting collaborating elements has been developed. Its description is given in [2]. In many cases the solutions proposed in the frame of the GPS system do not concern lar ge-size objects which are produced mainly in shipbuilding industry . Scale of the dimensional quality problem is lage in production enterprises of a technological level similar to that of Polish shipyards. As results from the author 's experience in such shipyards the increase of labour consumption resulting from repair of dimensional quality errors reaches as much as $30 \div 40 \%$ of total labour consumption for building ship hull.

The problems in question are not widely discussed. Moreover the published solutions are mainly dedicated to shipyards of a high-level technological support. Such level has been reached by realization of complex restructuring projects for shipbuilding industry at the expense of very high initial outlays. To use the then-presented solutions in production enterprises of characteristics close to Polish shipyards is very difficult, if not impossible at all. Their features are discussed below. 


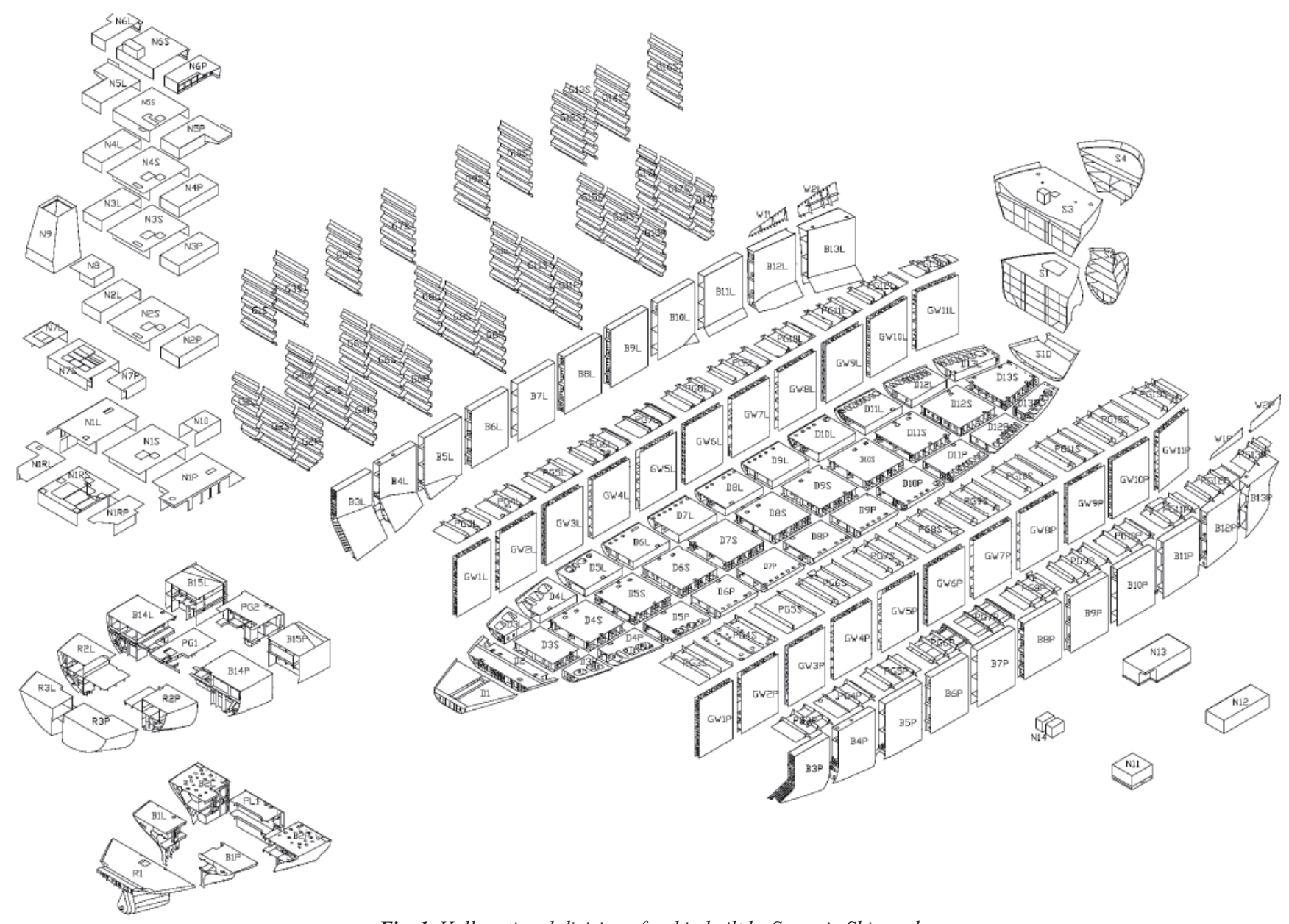

Fig. 1. Hull sectional division of a ship built by Szczecin Shipyard

\section{ASSUMPTIONS AND LIMITATIONS}

As already mentioned the dimensional quality problems in production enterprises of characteristics similar to shipyards are very individual. It arises first of all from the following features:

- high production intensity

- large changeability of manufacturing process, that makes permanent control of dimensions during the process necessary

- seperate dimensional quality requirements for particular units

- low investment possibilities

- a lack of roofing over hull assembly sites (which produces significant problems resulting from deformations due to insolation)

- a large degree of co-operation (many structural elements,e. g. hull sections and blocks, are produced by subcontractors in various manufacturing conditions).

The conditions make application of versatile measurment systems very difficult and even impossible in most cases.

Moreover application of electronic measurement instrumentation which requires specialty measuring stands as well as significant financial outlays is rather troublesome.

The measuring methods most used in the above mentioned cases are those based on optical measuring instruments and, as far as conditions allow electronic tachymeters with application of the pole measurment method. The crucial assumption (requirement) put for elaboration of solutions presented in this paper was to use the measurement methods which have been applied so far.
Moreover the necessity of application of optical measuring instruments results from the high degree of co-operation in the area of prefabrication of hull sections. In most cases the subcontarctors do not have at their disposal production sites suitably prepared to carrying out dimensional quality control by using advanced measuring techniques.

\section{IDEA OF DYNAMICAL DIMENSIONAL CONTROL OF LARGE STEEL STRUCTURES IN PRODUCTION ENTERPRISES OF MEDIUM- AND LOW- LEVEL TECHNOLOGICAL SUPPORT}

In structurebuilding process measuring processes intertwine with technological ones. We deal here with a complex technical system, to use system approach is therefore necessary for analysis of measurement control operations. Geometrical control system in the area of shipbuilding metrology is defined by this author as a set of elements of metrological operations, their manners and set of couplings between the elements and those of the technological process itself.The models in question make dynamical control of measuring processes possible on the basis of necessary accuracy standards as well as information gained from production process under way . The accuracy standards are determined by required dimensional accuracy of prefabricated and assembled hull structure elements. The problem is discussed in the further part concerning verification of the results obtained in modelling process.

The discussed models represent control and measurement systems mainly by using mathematical description as well as - to a much smaller extent - linguistic one.This is a simplified description of the process features considered important with 
regard to application of the model. In the discussed case the task of the model is to indicate optimum parameters of control and measurement processes (i.e. their system).

The parameters are first of all the following:

- measurement accuracy

- measurement method to be used

- kind and model of measuring instrument

- co-ordinates of measuring instrument stand

- co-ordinates of base points.

Number of the parameters and their characteristics depend on a type of measuring task.

The overall schematic diagram of the discussed models is presented in Fig. 2.

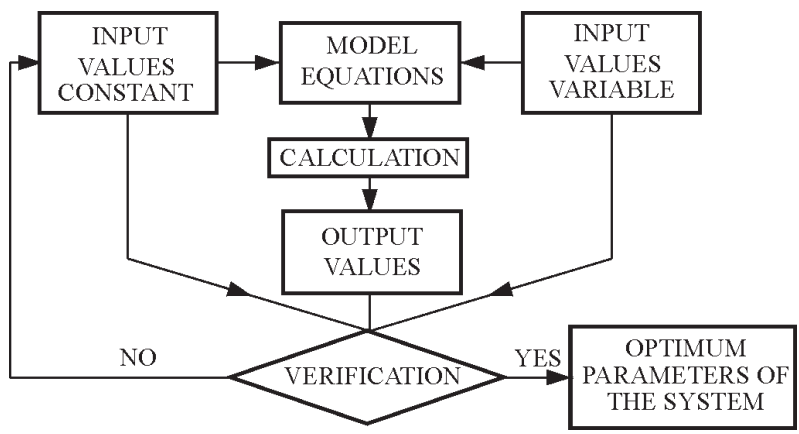

Fig. 2. Schematic diagram of modelling process

The modelling process begins from detail description of a measurement task for which control \& measurement system has to be designed. Next, the following input quantities should be determined:

- constants characteristic for a given shipyard, available in the designing phase

- variables which charecterize changes occurring in production process and affecting a modeled system.

The successive phases of modelling process are as follows: - calculation processes performed on the basis of model' $\mathrm{s}$ equations

- verification process.

„The heart" of the system is composed of the model' s equations which determine input quantities on the basis of which are determined parameters subjected to verification in the successive step. The equations are elaborated on the basis of mathematical description of measurement methods. In order to present the described system it is necessary to highlight measurement methods used in shipbuilding industry, and their mathematical models.

\section{MEASUREMENT METHODS}

As already mentioned the control \& measurement operations during building process of ship hull are usually performed with the use of the pole method based on electronic tachymeters, as well as classical methods (the optical levelling method and reference line method) by using optical measuring instruments.

The pole method based on tachymeters is widely known and used during building process of lage structures. Its application to shipbuilding metrology was described a. o. in [4]. And, as results from the author's experience, the shipbuilding metrology based on the classical optical instruments should be highlighted especially as regards its mathematical description on which further analyses are based.
The main characteristic feature of the discussed measurement methods is the necessity of carrying out measurements within inclined co-ordinate frames as well as in dynamically varying systems as ship hull assembling sites are usually inclined relative to levelling plane. Moreover a part of ship's outfitting operations is carried out on ships lying along berth (floating ships undergo oscillating motions). The conditions make direct application of typical measuring methods based on constant levelling plane determined by means of levels or self-levelling mechanisms, difficult and even impossible in many cases.The methods in question allow for making the reference frame independent of the levelling plane. Below is presented a short description of the mentioned methods as well as a procedure for elaborating their mathematical models.

\section{REFERENCE LINE METHOD}

The reference line method finds broad application both to measurement of deformations and assembling control of objects. It is known in a few versions which dif fer to each other by measuring technique and kind of quantities to be determined. Measurements performed by using the method mostly relate to two mutually perpendicular planes: vertical one containing reference straight line, and horizontal one. During control \& measurement operations carried out in ship building process the two -plane system must be replaced - for the above discussed reasons (to make the reference system independent of the levelling plane) - with the system of two mutually perpendicular planes $\Pi_{1}, \Pi_{2}$, the first of which is parallel to ship's base plane (Fig. 3).

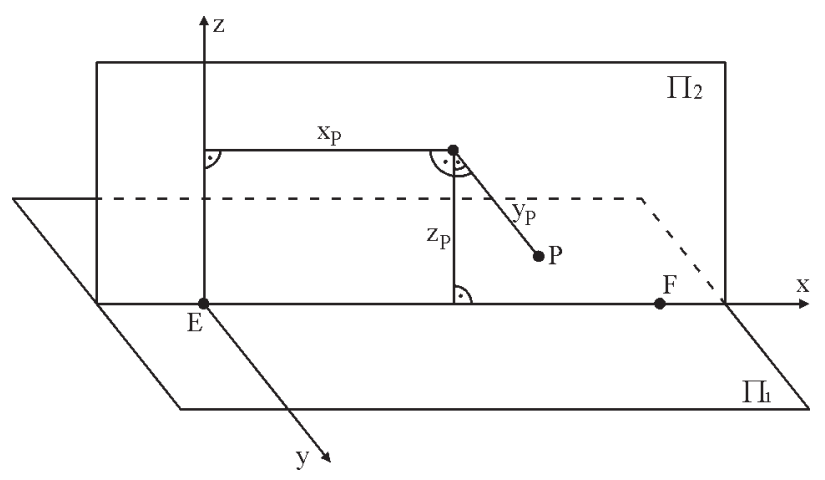

Fig. 3. Reference line method

The reference straight line is usually formed by sight line of theodolite or levelling instrument. The method in question is used to determine the coordinates $\mathrm{y}_{\mathrm{p}} \mathrm{z}_{\mathrm{p}}$; the coordinate $\mathrm{x}_{\mathrm{P}}$ plays an auxiliary role (as a calculation parameter). For every quantity other measuring technique is used. It results from that the quantity $\mathrm{y}_{\mathrm{p}}$ is related to the plane $\Pi_{2}$, whereas $\mathrm{z}_{\mathrm{p}}$ to $\Pi_{1}$. Hence seperate mathematical descriptions were elaborated for determining the coordinates $\mathrm{y}_{\mathrm{p}}$ and $\mathrm{z}_{\mathrm{p}}$. The coordinates $\mathrm{z}_{\mathrm{p}}$ describe values of the sections perpendicular to the reference line and located on the plane $\Pi_{2}$. Fig. 4 was used to elaborate the mathematical model for determining the quantity $\mathrm{z}_{\mathrm{p}}$.

In the points $\mathrm{E}, \mathrm{F}$, and $\mathrm{P}$ measuring rods are placed perpendicularly to the $\Pi_{1}$. The sight line of measuring instrument determines readouts of $h_{\mathrm{E}}, \mathrm{h}_{\mathrm{F}}$ and $\mathrm{h}_{\mathrm{p}}$. The searchedfor value of $z_{\mathrm{p}}$ is determined by using the following relation:

$$
\mathrm{z}_{\mathrm{P}}=\overline{\mathrm{P}^{\prime} \mathrm{P}^{\prime \prime}}-\mathrm{h}_{\mathrm{P}}
$$

On transformation the following is obtained:

$$
\mathrm{z}_{\mathrm{P}}=\mathrm{h}_{\mathrm{E}}+\frac{\left(\mathrm{h}_{\mathrm{F}}-\mathrm{h}_{\mathrm{E}}\right)}{\mathrm{x}_{\mathrm{F}}} \mathrm{x}_{\mathrm{P}}-\mathrm{h}_{\mathrm{P}}
$$




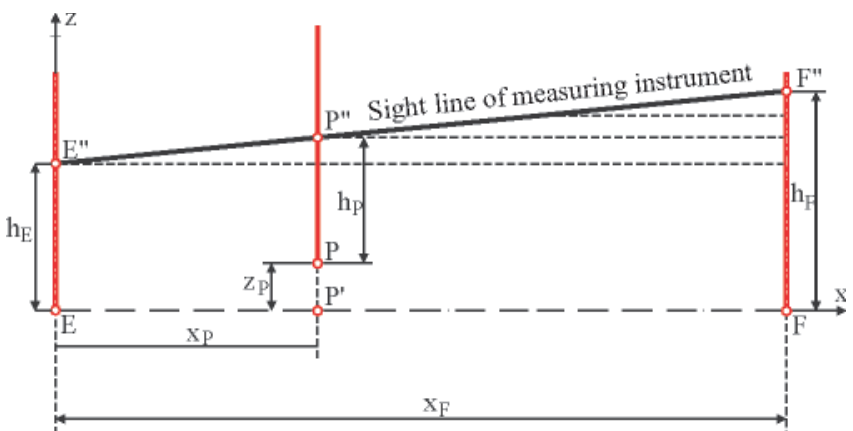

Fig. 4. Reference line method

The above given formula constitutes the mathematical model for determining the quantity $z$ by means of the reference line method.

To carry out calculations by using Eq.(2) on the assembling stand is labour-consuming. To shorten them the measurement executor tries to reach the situation when $h_{\mathrm{E}}=\mathrm{h}_{\mathrm{p}}$. In such case the determining of the quantity $z_{\mathrm{p}}$ is simplified to the following form:

$$
\mathrm{z}_{\mathrm{P}}=\mathrm{h}_{\mathrm{E}}-\mathrm{h}_{\mathrm{P}}
$$

that improves the measuring process considerably.

The coordinates $\mathrm{y}_{\mathrm{P}}$ describe the sections perpendicular to the reference line and parallel to the plane $\prod_{1}$ To determine the quantities, an instrument whose sight line is able to build the plane $\Pi_{2}$ perpendicular to $\Pi_{1}$ and directed along the reference line $\mathrm{EF}$, is necessary. The searched-for value is equal to the distance of the point $\mathrm{P}$ from the plane $\Pi_{2}$ (Fig. 5).

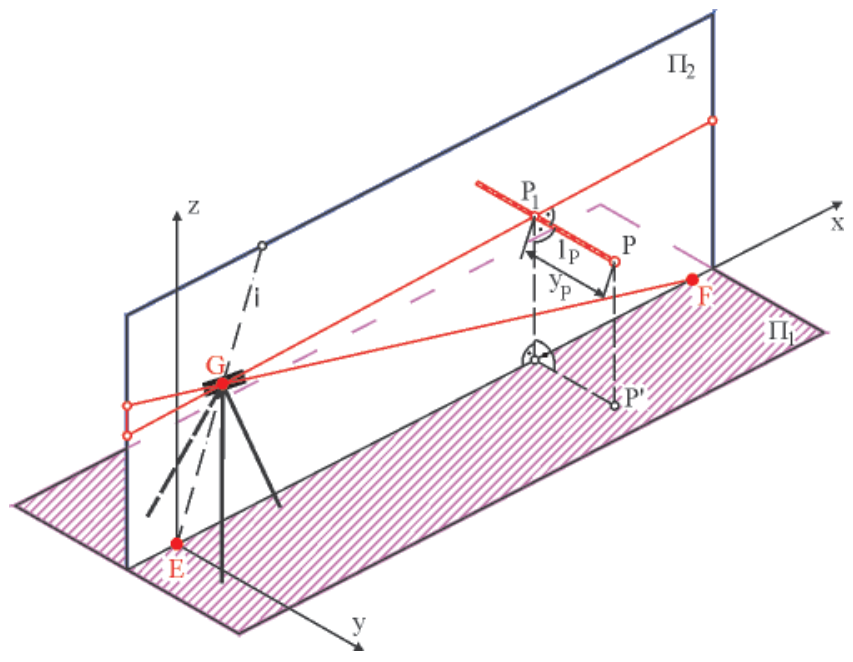

Fig. 5. Reference line method

Fig. 5 was used to elaborate the mathematical model for determining the quantity $\mathrm{y}_{\mathrm{p}}$. The model in question was formed on the basis of the expression describing the distance of the point $\mathrm{P}\left(\mathrm{x}_{\mathrm{P}}, 1_{\mathrm{p}} \mathrm{z}_{\mathrm{P}}\right)$ from the plane $\Pi_{2}$ which contains the points $E\left(x_{E}, y_{E}, z_{E}\right), F\left(x_{F}, y_{F}, z_{F}\right), G\left(x_{G}, y_{G}, z_{G}\right)$ :

$$
\mathrm{y}_{\mathrm{P}}=\frac{\mathrm{R} 1_{\mathrm{P}}+\mathrm{Sx}_{\mathrm{P}}+\mathrm{Tz_{ \textrm {P } }}+\mathrm{U}}{\sqrt{\mathrm{R}^{2}+\mathrm{S}^{2}+\mathrm{T}^{2}}}
$$

where:

$$
\begin{aligned}
R= & \left(x_{E} \cdot z_{F}-x_{E} \cdot z_{G}-x_{F} \cdot z_{E}+x_{F} \cdot z_{G}+x_{G} \cdot z_{E}-x_{G} \cdot z_{F}\right) \\
S= & \left(-y_{E} \cdot z_{F}-y_{F} \cdot z_{G}-y_{G} \cdot z_{E}+y_{E} \cdot z_{G}+y_{F} \cdot z_{E}-y_{G} \cdot z_{F}\right) \\
T= & \left(y_{F} \cdot x_{G}-y_{F} \cdot x_{E}+y_{G} \cdot x_{E}+y_{E} \cdot x_{F}-x_{F} \cdot y_{G}-y_{E} \cdot x_{G}\right) \\
U= & \left(-y_{G} \cdot x_{E} \cdot z_{F}-y_{E} \cdot x_{F} \cdot z_{G}+y_{G} \cdot x_{F} \cdot z_{E}+y_{E} \cdot x_{G} \cdot z_{F}+\right. \\
& \left.\quad-y_{F} \cdot x_{E} \cdot z_{G}-y_{F} \cdot x_{G} \cdot z_{E}\right) \\
R l_{P} & +S x_{P}+T z_{P}+U>0
\end{aligned}
$$

On the assumption that the auxiliary coordinate system Oxyz associated with the planes $\Pi_{1}$ and $\Pi_{2}$ satisfies the following conditions:

- $\mathrm{x}$ - axis of the system forms edge of intersection of the planes $\Pi_{1}$ and $\Pi_{2}$

- $\mathrm{y}-$ axis lays on the plane $\Pi_{1}$

- $\mathrm{z}$ - axis lays on the plane $\Pi_{2}$

the following can be assumed:

$\left.\begin{array}{ll}\cdot \mathrm{y} & \mathrm{E}=\mathrm{y}_{\mathrm{F}}=\mathrm{y}_{\mathrm{G}}=0 \\ \cdot \mathrm{z} & \mathrm{E}=\mathrm{z}_{\mathrm{F}}=0 \\ \cdot \mathrm{x} & \mathrm{E}=0\end{array}\right\}$

On insertion of Eq. (5) to Eq. (4) the following was obtained:

$$
\mathrm{y}_{\mathrm{P}}=1_{\mathrm{P}}
$$

As results from Eq. (6), in the assumed system the measuring of the quantity $\mathrm{y}_{\mathrm{P}}$ is equivalent to the reading-out of value of the quantity $p_{p}$ on the measuring rod put against the object in the point Pand placed perpendicularly to the plane $\prod_{2}$ The compexity degree of Eq. (4) makes calculating y - values greatly difficult. In practice one tries to reach the situation where the conditions (5) are satisfied that makes using Eq. (6) for the calculations possible.

\section{OPTICAL LEVELLING METHOD}

As already mentioned in shipbuilding metrology it is necessary to relate measurements to planes or near -planar surfaces inclined relative to levelling plane by the small angle $\Theta$. In such cases appropriate measurements are performed with the use of the optical levelling method in which the reference level is not used, but the auxiliary plane $\Pi_{c}$ is applied (Fig. 6) relative to which measurements are carried out. The method may be applied both to carrying out measurements on landbased assembling stands and on floating ships (floating dock, ship after launching). It is schematically presented in Fig. 6.

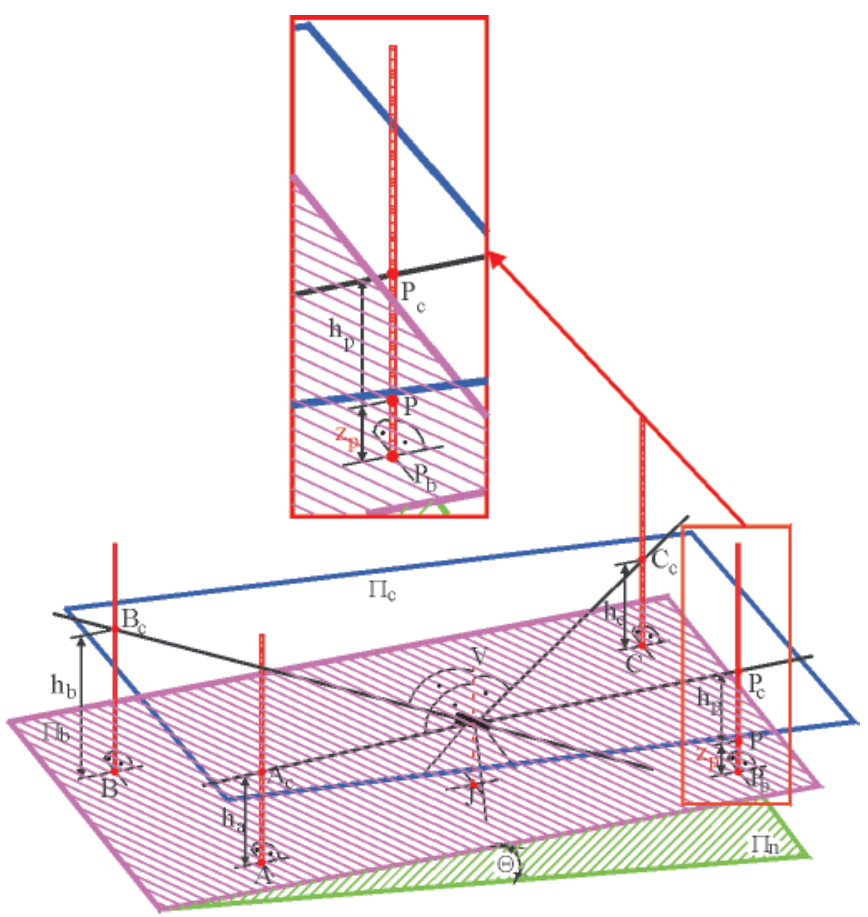

Fig. 6. Optical levelling method

The crucial task in conducting the measurements by means of the optical levelling method is to determine the coordinates 
$\mathrm{Z}_{\mathrm{p}}$ of the points $\mathrm{P}_{\mathrm{i}}$ in an orto-cartesian coordinate system 0xyz. In the case when the plane $\Pi_{b}$ constitutes the reference surface, the axes $\mathrm{x}$, $\mathrm{y}$ of the system are assumed to lay just on the plane, giving them this way orientation appropriate to given purposs. The plane $\Pi_{b}$ is determined by three suitably chosen points $A, B, C$ which usually lay on a measured structure. The points are called the base.

Value of $\mathrm{z}_{\mathrm{p}}$ is calculated in accordance with the following relation:

$$
\begin{gathered}
\mathrm{Z}_{\mathrm{P}}=\mathrm{Z}_{\mathrm{P}_{\mathrm{C}}}-\mathrm{h}_{\mathrm{P}} \\
\text { where: } \\
\mathrm{z}_{\mathrm{P}_{\mathrm{C}}}-,, \mathrm{Z} \text { " coordinate of the point } \mathrm{P}_{\mathrm{C}} \text {. }
\end{gathered}
$$

Value of $\mathrm{z}_{\mathrm{P}_{\mathrm{C}}}$ can be determined by using the relation which expresses the equation of the plane $\Pi_{\mathrm{c}}$ which contains the points

$$
\begin{gathered}
A\left(x_{A}, y_{A}, h_{A}\right), B\left(x_{B}, y_{B}, h_{B}\right), C\left(x_{C}, y_{C}, h_{C}\right): \\
\left|\begin{array}{llll}
x_{P} & y_{P} & z_{P_{C}} & 1 \\
x_{A} & y_{A} & h_{A} & 1 \\
x_{B} & y_{B} & h_{B} & 1 \\
x_{C} & y_{C} & h_{C} & 1
\end{array}\right|=0
\end{gathered}
$$

On transformation, Eq. (17) can be presented as follows:

$$
\begin{gathered}
\mathrm{z}_{\mathrm{P}_{\mathrm{C}}}=\frac{\left(\Delta \mathrm{x}_{\mathrm{AB}} \mathrm{y}_{\mathrm{P}}+\Delta \mathrm{x}_{\mathrm{BP}} \mathrm{y}_{\mathrm{A}}-\Delta \mathrm{x}_{\mathrm{AP}} \mathrm{y}_{\mathrm{B}}\right) \mathrm{h}_{\mathrm{C}}+\left(\Delta \mathrm{x}_{\mathrm{AP}} \mathrm{y}_{\mathrm{C}}-\Delta \mathrm{x}_{\mathrm{AC}} \mathrm{y}_{\mathrm{P}}-\Delta \mathrm{x}_{\mathrm{CP}} \mathrm{y}_{\mathrm{A}}\right) \mathrm{h}_{\mathrm{B}}+\left(\Delta \mathrm{x}_{\mathrm{BC}} \mathrm{y}_{\mathrm{P}}-\Delta \mathrm{x}_{\mathrm{BP}} \mathrm{y}_{\mathrm{C}}+\Delta \mathrm{x}_{\mathrm{CP}} \mathrm{y}_{\mathrm{B}}\right) \mathrm{h}_{\mathrm{A}}}{\Delta \mathrm{x}_{\mathrm{AP}} \mathrm{y}_{\mathrm{C}}+\Delta \mathrm{x}_{\mathrm{BC}} \mathrm{y}_{\mathrm{A}}-\Delta \mathrm{x}_{\mathrm{AC}} \mathrm{y}_{\mathrm{P}}} \\
\text { where: } \\
\Delta \mathrm{x}_{\mathrm{AB}}=\mathrm{x}_{\mathrm{B}}-\mathrm{x}_{\mathrm{A}} \\
\Delta \mathrm{x}_{\mathrm{BP}}=\mathrm{x}_{\mathrm{P}}-\mathrm{x}_{\mathrm{B}} \\
\Delta \mathrm{x}_{\mathrm{AP}}=\mathrm{x}_{\mathrm{P}}-\mathrm{x}_{\mathrm{A}} \\
\Delta \mathrm{x}_{\mathrm{AC}}=\mathrm{x}_{\mathrm{C}}-\mathrm{x}_{\mathrm{A}} \\
\Delta \mathrm{x}_{\mathrm{CP}}=\mathrm{x}_{\mathrm{P}}-\mathrm{x}_{\mathrm{C}} \\
\Delta \mathrm{x}_{\mathrm{BC}}=\mathrm{x}_{\mathrm{C}}-\mathrm{x}_{\mathrm{B}}
\end{gathered}
$$

On insertion of the right-hand side of Eq. (9) to Eq. (7) the following was obtained:

$$
\mathrm{z}_{\mathrm{P}}=\left(\frac{\left(\Delta \mathrm{x}_{\mathrm{AB}} \mathrm{y}_{\mathrm{P}}+\Delta \mathrm{x}_{\mathrm{BP}} \mathrm{y}_{\mathrm{A}}-\Delta \mathrm{x}_{\mathrm{AP}} \mathrm{y}_{\mathrm{B}}\right) \mathrm{h}_{\mathrm{C}}+\left(\Delta \mathrm{x}_{\mathrm{AP}} \mathrm{y}_{\mathrm{C}}-\Delta \mathrm{x}_{\mathrm{AC}} \mathrm{y}_{\mathrm{P}}-\Delta \mathrm{x}_{\mathrm{CP}} \mathrm{y}\right)_{\mathrm{A}} \mathrm{h}_{\mathrm{B}}+\left(\Delta \mathrm{x}_{\mathrm{BC}} \mathrm{y}_{\mathrm{P}}-\Delta \mathrm{x}_{\mathrm{BP}} \mathrm{y}_{\mathrm{C}}+\Delta \mathrm{x}_{\mathrm{CP}} \mathrm{y}_{\mathrm{B}}\right) \mathrm{h}_{\mathrm{A}}}{\Delta \mathrm{x}_{\mathrm{AB}} \mathrm{y}_{\mathrm{C}}+\Delta \mathrm{x}_{\mathrm{BC}} \mathrm{y}_{\mathrm{A}}-\Delta \mathrm{x}_{\mathrm{AC}} \mathrm{y}_{\mathrm{B}}}-\mathrm{h}_{\mathrm{P}}\right.
$$

This is the mathematical model of the optical levelling method.

The carrying out of calculations on the basis of the above given expression makes the control \& measurement process much longer. The calculations in question become simpler when $\mathrm{h}_{\mathrm{A}}=\mathrm{h}_{\mathrm{B}}=\mathrm{h}_{\mathrm{C}}$. In such situation Eq. (10) takes the following form:

$$
\mathrm{z}_{\mathrm{P}}=\mathrm{h}_{\mathrm{A}}-\mathrm{h}_{\mathrm{P}}
$$

In practice one should aim at the situation when to apply Eq. (11) is possible as it greatly simplifies calculation process.

By analysing the above presented mathematical descriptions of the measurement methods it is easy to come to the conclusion that accuracy of determining measured values is first of all affected by errors of readouts taken from measuring rods. The quantities are described in the subject-matter literature, e.g. [3], by means of some approximate formulas which are decisively too-low exact for purposes of shipbuilding metrologyTherefore the quantities were determined experimentally . To this end a special testing device was elaborated by using which tests were performed for selected measuring instruments. In consequence of the tests regression equations which describe values of the errors in question, were obtained depending on aimed length values. The equations were elaborated individually both for particular instruments and measuring stands. The obtained results confirmed the above given thesis on too-low exactness of the approximate formulas describing the errors in question.
A way of making use of the obtained equations has been presented with the use of a calculation example given below.

\section{MODEL EQUATIONS}

During modelling process calculations are carried out on the basis of model equations elaborated by using mathematical description. The models were used for elaborating accuracy description of measurements performed by using particular methods. The description was prepared with the use of the principle of proliferation of mean errors. As a result of the operation the following was obtained:

For optical levelling:

$$
\begin{gathered}
\mathrm{m}_{\mathrm{z}_{\mathrm{i}}}^{2}=\left(\frac{\partial \mathrm{z}_{\mathrm{P}_{\mathrm{i}}}}{\partial \mathrm{h}_{\mathrm{A}}}\right)^{2} \mathrm{~m}_{\mathrm{h}_{\mathrm{A}}}^{2}+\left(\frac{\partial \mathrm{z}_{\mathrm{P}_{\mathrm{i}}}}{\partial \mathrm{h}_{\mathrm{B}}}\right)^{2} \mathrm{~m}_{\mathrm{h}_{\mathrm{B}}}^{2}+\left(\frac{\partial \mathrm{z}_{\mathrm{P}_{\mathrm{i}}}}{\partial \mathrm{h}_{\mathrm{C}}}\right)^{2} \mathrm{~m}_{\mathrm{h}_{\mathrm{C}}}^{2}+ \\
+\left(\frac{\partial \mathrm{z}_{\mathrm{P}_{\mathrm{i}}}}{\partial \mathrm{h}_{\mathrm{P}_{\mathrm{i}}}}\right)^{2} \mathrm{~m}_{\mathrm{h}_{\mathrm{P}}}^{2}+\left(\frac{\partial \mathrm{z}_{\mathrm{P}_{\mathrm{i}}}}{\partial \mathrm{x}_{\mathrm{A}}}\right)^{2} \mathrm{~m}_{\mathrm{x}_{\mathrm{A}}}^{2}+\left(\frac{\partial \mathrm{z}_{\mathrm{P}_{\mathrm{i}}}}{\partial \mathrm{y}_{\mathrm{A}}}\right)^{2} \mathrm{~m}_{\mathrm{y}_{\mathrm{A}}}^{2}+ \\
+\left(\frac{\partial \mathrm{z}_{\mathrm{P}_{\mathrm{i}}}}{\partial \mathrm{x}_{\mathrm{B}}}\right)^{2} \mathrm{~m}_{\mathrm{x}_{\mathrm{B}}}^{2}+\left(\frac{\partial \mathrm{z}_{\mathrm{P}_{\mathrm{i}}}}{\partial \mathrm{y}_{\mathrm{B}}}\right)^{2} \mathrm{~m}_{\mathrm{y}_{\mathrm{B}}}^{2}+\left(\frac{\partial \mathrm{z}_{\mathrm{P}_{\mathrm{i}}}}{\partial \mathrm{x}_{\mathrm{C}}}\right)^{2} \mathrm{~m}_{\mathrm{x}_{\mathrm{C}}}^{2}+ \\
+\left(\frac{\partial \mathrm{z}_{\mathrm{P}_{\mathrm{i}}}}{\partial \mathrm{y}_{\mathrm{C}}}\right)^{2} \mathrm{~m}_{\mathrm{y}_{\mathrm{C}}}^{2}+\left(\frac{\partial \mathrm{z}_{\mathrm{P}_{\mathrm{i}}}}{\partial \mathrm{x}_{\mathrm{P}_{\mathrm{i}}}}\right)^{2} \mathrm{~m}_{\mathrm{x}_{\mathrm{P}_{\mathrm{i}}}}^{2}+\left(\frac{\partial \mathrm{z}_{\mathrm{P}_{\mathrm{i}}}}{\partial \mathrm{y}_{\mathrm{P}_{\mathrm{i}}}}\right)^{2} \mathrm{~m}_{\mathrm{y}_{\mathrm{P}_{\mathrm{i}}}}^{2} \\
\mathrm{i}=1,2, \ldots \mathrm{n}
\end{gathered}
$$


where:

$\mathrm{n}$

number of points $P$, $\mathrm{m}_{\mathrm{h}_{\mathrm{A}}}, \mathrm{m}_{\mathrm{h}_{\mathrm{B}}}, \mathrm{m}_{\mathrm{h}_{\mathrm{C}}}, \mathrm{m}_{\mathrm{h}_{\mathrm{P}_{\mathrm{i}}}}-\begin{aligned} & \text { standard deviations of respective } \\ & \text { readouts from measuring rods }\end{aligned}$

$m_{x_{A}}, m_{y_{A}}, m_{x_{B}}$,

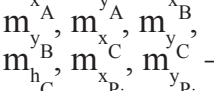

standard deviations of determination of coordinates of the points $\mathrm{A}, \mathrm{B}, \mathrm{C}$ and $\mathrm{P}_{\mathrm{i}}$.

To the variable $z_{\mathrm{p}}$ the parameter, ,i” was introduced, $\left(\mathrm{z}_{\mathrm{p}}\right)$, which describes a number of the points $\mathrm{P}$ whose coordinates „Z" are to be determined in one measuring process.

For the reference line method the following was achieved:

For $z_{\mathrm{p}}$ :

$$
\begin{gathered}
\mathrm{m}_{\mathrm{z}_{\mathrm{P}}}^{2}=\left(\frac{\partial \mathrm{z}_{\mathrm{P}}}{\partial \mathrm{h}_{\mathrm{E}}}\right)^{2} \mathrm{~m}_{\mathrm{h}_{\mathrm{E}}}^{2}+\left(\frac{\partial \mathrm{z}_{\mathrm{P}}}{\partial \mathrm{h}_{\mathrm{B}}}\right)^{2} \mathrm{~m}_{\mathrm{h}_{\mathrm{F}}}^{2}+ \\
+\left(\frac{\partial \mathrm{z}_{\mathrm{P}}}{\partial \mathrm{h}_{\mathrm{P}}}\right)^{2} \mathrm{~m}_{\mathrm{h}_{\mathrm{P}}}^{2}+\left(\frac{\partial \mathrm{z}_{\mathrm{P}}}{\partial \mathrm{x}_{\mathrm{F}}}\right)^{2} \mathrm{~m}_{\mathrm{x}_{\mathrm{F}}}^{2}+\left(\frac{\partial \mathrm{z}_{\mathrm{P}}}{\partial \mathrm{x}_{\mathrm{P}}}\right)^{2} \mathrm{~m}_{\mathrm{x}_{\mathrm{P}}}^{2}
\end{gathered}
$$

where:

$$
\begin{aligned}
& \mathrm{X}_{\mathrm{E}}, \mathrm{X}_{\mathrm{P}} \quad-\text { coordinates of the points } \mathrm{E} \text { and } \mathrm{P} \\
& h_{E}, h_{F}, h_{P} \quad-\quad \text { readouts from measuring rods placed in the } \\
& \text { points } \mathrm{E}, \mathrm{F} \text {, and } \mathrm{P} \\
& \mathrm{m}_{\mathrm{x}_{\mathrm{E}}}, \mathrm{m}_{\mathrm{x}_{\mathrm{P}}} \quad-\text { standard deviations of determination of } \\
& \text { coordinates of the points } \mathrm{E}, \mathrm{P} \\
& \mathrm{m}_{\mathrm{h}_{\mathrm{E}}}, \mathrm{m}_{\mathrm{h}_{\mathrm{F}}}, \mathrm{m}_{\mathrm{h}_{\mathrm{p}}}-\text { standard deviations of appropriate readouts } \\
& \text { from measuring rods }
\end{aligned}
$$

For $\mathrm{y}_{\mathrm{p}}$ :

$$
\begin{gathered}
\mathrm{m}_{\mathrm{y}_{\mathrm{P}}}^{2}=\left(\frac{\partial \mathrm{y}_{\mathrm{P}}}{\partial \mathrm{x}_{\mathrm{E}}}\right)^{2} \mathrm{~m}_{\mathrm{x}_{\mathrm{E}}}^{2}+\left(\frac{\partial \mathrm{y}_{\mathrm{P}}}{\partial \mathrm{y}_{\mathrm{E}}}\right)^{2} \mathrm{~m}_{\mathrm{y}_{\mathrm{E}}}^{2}+\left(\frac{\partial \mathrm{y}_{\mathrm{P}}}{\partial \mathrm{z}_{\mathrm{E}}}\right)^{2} \mathrm{~m}_{\mathrm{z}_{\mathrm{E}}}^{2}+ \\
+\left(\frac{\partial \mathrm{y}_{\mathrm{P}}}{\partial \mathrm{x}_{\mathrm{F}}}\right)^{2} \mathrm{~m}_{\mathrm{x}_{\mathrm{F}}}^{2}+\left(\frac{\partial \mathrm{y}_{\mathrm{P}}}{\partial \mathrm{y}_{\mathrm{F}}}\right)^{2} \mathrm{~m}_{\mathrm{y}_{\mathrm{F}}}^{2}+\left(\frac{\partial \mathrm{y}_{\mathrm{P}}}{\partial \mathrm{z}_{\mathrm{F}}}\right)^{2} \mathrm{~m}_{\mathrm{z}_{\mathrm{F}}}^{2}+ \\
+\left(\frac{\partial \mathrm{y}_{\mathrm{P}}}{\partial \mathrm{x}_{\mathrm{G}}}\right)^{2} \mathrm{~m}_{\mathrm{x}_{\mathrm{G}}}^{2}+\left(\frac{\partial \mathrm{y}_{\mathrm{P}}}{\partial \mathrm{y}_{\mathrm{G}}}\right)^{2} \mathrm{~m}_{\mathrm{y}_{\mathrm{G}}}^{2}+\left(\frac{\partial \mathrm{y}_{\mathrm{P}}}{\partial \mathrm{z}_{\mathrm{G}}}\right)^{2} \mathrm{~m}_{\mathrm{z}_{\mathrm{G}}}^{2}+ \\
+\left(\frac{\partial \mathrm{y}_{\mathrm{P}}}{\partial \mathrm{x}_{\mathrm{P}}}\right)^{2} \mathrm{~m}_{\mathrm{x}_{\mathrm{P}}}^{2}+\left(\frac{\partial \mathrm{y}_{\mathrm{P}}}{\partial \mathrm{l}_{\mathrm{P}}}\right)^{2} \mathrm{~m}_{\mathrm{P}}^{2}+\left(\frac{\partial \mathrm{y}_{\mathrm{P}}}{\partial \mathrm{z}_{\mathrm{P}}}\right)^{2} \mathrm{~m}_{\mathrm{z}_{\mathrm{P}}}^{2}
\end{gathered}
$$

where:

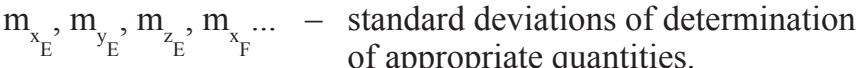

Mathematical model of the pole method as well as description of accuracy of measurements carried out by using the method, was presented in [4].

\section{CALCULATIONS AND THEIR VERIFICATION}

Description of procedure of using particular equations would require a very extensive elaboration.Therefore the author considered it reasonable to present only a selected calculation process based on the equations of the optical levelling method. Calculation procedures for the remaining equations are carried out by using similar principles.
The calculations consist in finding optimum parameters (decision variables) for assumed input data. To this and, appropriate optimization methods were selected to take into account complexity of particular models. In the case in question searching for optimum parameters consists in finding an extremum of the function (15) which describes standard deviation of a given measuring process. In the case of measurements carried out by means of the optical levelling method the function takes the following form:

$$
\begin{gathered}
\mathrm{F}=\sum_{\mathrm{i}=1}^{\mathrm{n}} \mathrm{r}_{\mathrm{z}_{\mathrm{P}_{\mathrm{i}}}} \rightarrow \min \\
\mathrm{i}=1,2, \ldots \mathrm{n}
\end{gathered}
$$

where:

$\mathrm{n} \quad-$ number of the points $\mathrm{P}$ (measured ones),

$r_{z_{P_{i}}}-$ quantity which expresses determination accuracy of the coordinate ,z" for a given point $\mathrm{P}_{\mathrm{i}}$.

The task is realized by finding a value of the vector

$\mathbf{u}$, Eq.(16), which minimizes the above given function.

$$
\mathbf{u}=\left[\mathrm{x}_{\mathrm{A}}, \mathrm{y}_{\mathrm{A}}, \mathrm{x}_{\mathrm{B}}, \mathrm{y}_{\mathrm{B}}, \mathrm{x}_{\mathrm{C},} \mathrm{y}_{\mathrm{C},} \mathrm{x}_{\mathrm{J}}, \mathrm{y}_{\mathrm{J}}\right]
$$

where:

$x_{A}, y_{A}, x_{B}, y_{B}, x_{C}, y_{C}-$ coordinates of the base points, $\mathrm{x}_{\mathrm{J}}, \mathrm{y}_{\mathrm{J}}$

- coordinates of the measuring stand.

The quantity $r_{7}$ was defined on the basis of Eq. (12). Its form is given by the following expression:

$$
\begin{aligned}
& \mathrm{r}_{\mathrm{z}_{\mathrm{i}}}=\left(\frac{\partial \mathrm{z}_{\mathrm{p}_{\mathrm{i}}}}{\partial \mathrm{h}_{\mathrm{A}}}\right)^{2} \cdot \mathrm{t}_{\mathrm{A}}^{2}+\left(\frac{\partial \mathrm{z}_{\mathrm{p}_{\mathrm{i}}}}{\partial \mathrm{h}_{\mathrm{B}}}\right)^{2} \cdot \mathrm{t}_{\mathrm{B}}^{2}+\left(\frac{\partial \mathrm{z}_{\mathrm{p}_{\mathrm{i}}}}{\partial \mathrm{h}_{\mathrm{C}}}\right)^{2} \cdot \mathrm{t}_{\mathrm{C}}^{2}+ \\
&+\left(\frac{\partial \mathrm{z}_{\mathrm{p}_{\mathrm{i}}}}{\partial \mathrm{h}_{\mathrm{P}_{\mathrm{i}}}}\right)^{2} \cdot \mathrm{t}_{\mathrm{P}_{\mathrm{i}}}^{2}+\left(\frac{\partial \mathrm{z}_{\mathrm{p}_{\mathrm{i}}}}{\partial \mathrm{x}_{\mathrm{A}}}\right)^{2}+\left(\frac{\partial \mathrm{z}_{\mathrm{p}_{\mathrm{i}}}}{\partial \mathrm{y}_{\mathrm{A}}}\right)^{2}+ \\
&+\left(\frac{\partial \mathrm{z}_{\mathrm{p}_{\mathrm{i}}}}{\partial \mathrm{x}_{\mathrm{B}}}\right)^{2}+\left(\frac{\partial \mathrm{z}_{\mathrm{p}_{\mathrm{i}}}}{\partial \mathrm{y}_{\mathrm{B}}}\right)^{2}+\left(\frac{\partial \mathrm{z}_{\mathrm{p}_{\mathrm{i}}}}{\partial \mathrm{x}_{\mathrm{C}}}\right)^{2}+ \\
&+\left(\frac{\partial \mathrm{z}_{\mathrm{p}_{\mathrm{i}}}}{\partial \mathrm{y}_{\mathrm{C}}}\right)^{2}+\left(\frac{\partial \mathrm{z}_{\mathrm{p}_{\mathrm{i}}}}{\partial \mathrm{x}_{\mathrm{P}_{\mathrm{i}}}}\right)^{2}+\left(\frac{\partial \mathrm{z}_{\mathrm{p}_{\mathrm{i}}}}{\partial \mathrm{y}_{\mathrm{P}_{\mathrm{i}}}}\right)^{2} \\
& \mathrm{i}=1,2, \ldots \mathrm{n}
\end{aligned}
$$

where:

$n-$ number of the points $P$

$\mathrm{t}_{\mathrm{A}}, \mathrm{t}_{\mathrm{B}}, \mathrm{t}_{\mathrm{C}}, \mathrm{t}_{\mathrm{P}_{\mathrm{i}}}$ - equations which describe standard deviation of

In the above given equation, values of standard deviations of determination of coordinates of particular points (see Eq. 12) were not taken into account as they can be considered constant and mutually identical. The performed calculation tests which consisted in inserting the constants to the optimization equation, showed that they did not affect the obtained results.

On the basis of the analysis of values of readout errors the following general form of the equations ,t" which desctribe standard deviation of readouts taken from measuring rod, was assumed:

where:

$\mathrm{l}=\mathrm{A}, \mathrm{B}, \mathrm{C}, \mathrm{P}_{\mathrm{i}}-$ location points of measuring rods,

a, b, c - coefficients of the equation which describes aiming error, 
$g_{1}=\sqrt{\left(x_{1}-x_{j}\right)^{2}+\left(y_{1}-y_{j}\right)^{2}}-$

$\mathrm{x}_{1}, \mathrm{x}_{\mathrm{J}}, \mathrm{y}_{1}, \mathrm{y}_{\mathrm{J}}$

sight line length for readouts taken from measuring rods located in the points $\mathrm{A}, \mathrm{B}, \mathrm{C}, \mathrm{P}_{\mathrm{i}}$ coordinates of the pointsA, B, C, $\mathrm{P}_{\mathrm{i}}$ as well as the measuring stand location point $\mathrm{J}$, respectively.

Values of the coefficients a, b, c of the equations ,t" result from a regression analysis performed for the obtained test results. Example results obtained for measurements carried out on slipway are presented in Fig. 7.

\section{$\mathrm{Ni}-02 \mathrm{IA}$ levelling instrument}

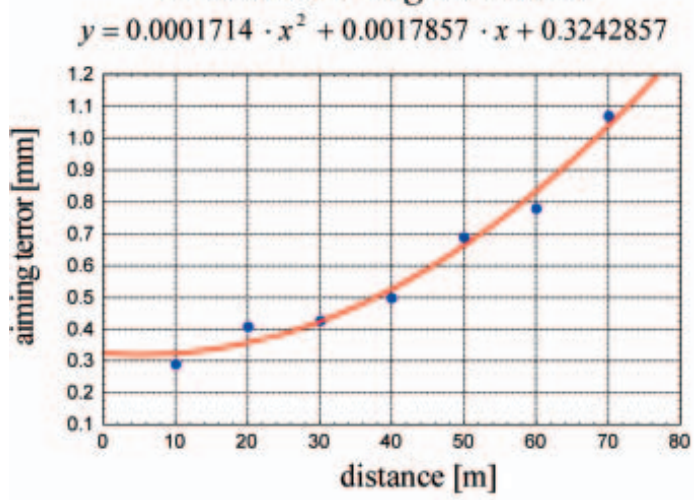

NI 004 levelling instrument $y=0.0000548 \cdot x^{2}+0.0039048 \cdot x+0.2385714$

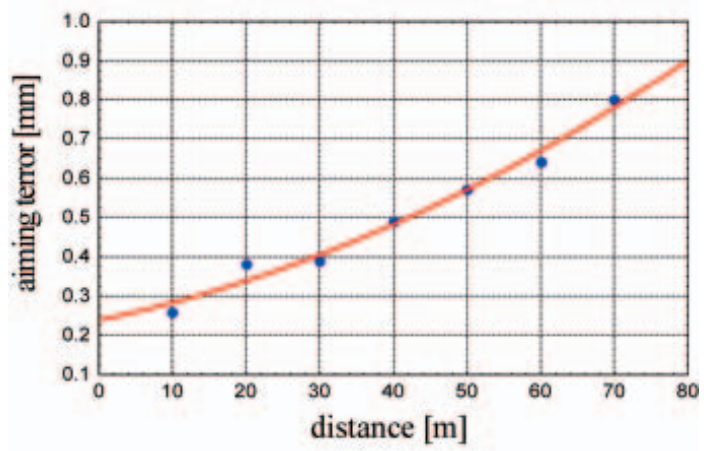

Fig. 7. Aiming error and reading-out error of values taken from measuring rod

Values of the searched-for vector u, Eq. (16), are to satisfy a given set of equations or inequalities - constraints. In the discussed optimization process the constraints result from an allowable location of measuring stand and base points. The location can be determined as an area of set of coordinates. If this is an area, the inequality constraints $\mathrm{a} \leq \mathrm{c} \leq \mathrm{b}$ are used, where $\mathrm{c}$ stands for the coordinate $\mathrm{x}$ or $\mathrm{y}$ of the point $\mathrm{A}, \mathrm{B}, \mathrm{C}, \mathrm{J}$, and $\mathrm{a}, \mathrm{b}$ consitute its lower and upper constraintAnd, if the set of coordinates is selected, the equality constraints: $\mathrm{c}=(\mathrm{d}, \ldots, \mathrm{d})$, where $d_{n}$ stand for values of the above mentioned coordinates, possible to be selected, are applied. In practice, location of base points is usually described by pairs of coordinates, but location of measuring instrument is indicated as an area.

In shipyard practice the coordinates , $\mathrm{Z}$ "are determined even for a dozen or so points P. It generates a dozen or so objective function components described by Eq. (17). Finally for the case in question a very complex formula has been obtained. To make applying the proposed solutions to shipbuilding metrology possible it is necessary to use a software by which it would be possible to fast elaborate and minimize the discussed functions.

Choice of such software and optimization method is rather subjective, depending on which computer and software is at hand. This author selected the Mathcad software. The choice was supported by multiple test calculations.The software offers two optimization methods:

- quasi-Newtonian one

- method of coupled gradients.

Calculations were performed by using both the methods. Differences in their results were found small. Better results (the objective function reached smaller values) were achieved by using the quasi-Newtonian method. Moreover superiority of the method was supported by that some problems with satisfying constraints arose when the method of coupled gradients was used. Summing up, the Mathcad software satisfies the following basic requirements for solving the calculation tasks of the kind:

- repeatability of results

- fulfilment of constraints

- short time of calculations (if suitable calculation modules are prepared in advance the time of realization of a complex optimization task by using the optical levelling method will not exceed one hour).

The detail description of the software as well as its optimization methods can be found a.o. in [1].

In order to better highlight the described process in the further part of the paper a simple example of the modelling process which covers also the optimization process based on the optical levelling method, is given. Of course there is possible to present more complex calculation processes. However it would require to make a seperate elaboration.

The next step of the modelling of a given system is the process of verification aimed at selection of parameters of the system, which make it possible to reach such accuracy of measuring process that satisfies technical and economical requirements. The technical requirements are associated with manufacturing tolerances on the basis of which minimum accuracy of measurements is determined. However the economical requirements are connected with cost of performance of measurements as well as accompanying operations (e.g. stopping production process, reorganization of a production stand on which measurements have to be carried out etc). The latter criterion is deemed secondary for the process in question as that orientated towards fulfilment of technical requirements is of priority importance.

In order to determine minimum accuracy to apply the commonly used ", golden principle of measuring technique" of Berndt, consisting in that standard deviation of a measurement should not exceed $10 \%$ of manufacturing tolerance, was proposed. And, in the case of obtaining a measurement result placed within uncertainty area (see Fig. 8) a technological analysis of production process under way should be performed. In the situation when the procedure indicates necessity of increasing measurement accuracy the modelling should be repeated for a modified technical criterion and to perform again measuring process.

In the case when obtained results do not satisfy verification criteria, input constant data should be changed by applying another:

- measuring instrument

- measuring method.

As already mentioned, the calculation and verification processes make it possible to determine the optimum parameters of modelled measurement process, such as:

- measurement accuracy

- measurement method to be used

- type and model of measuring instrument

- coordinates of measuring instrument stand

- coordinates of base points. 


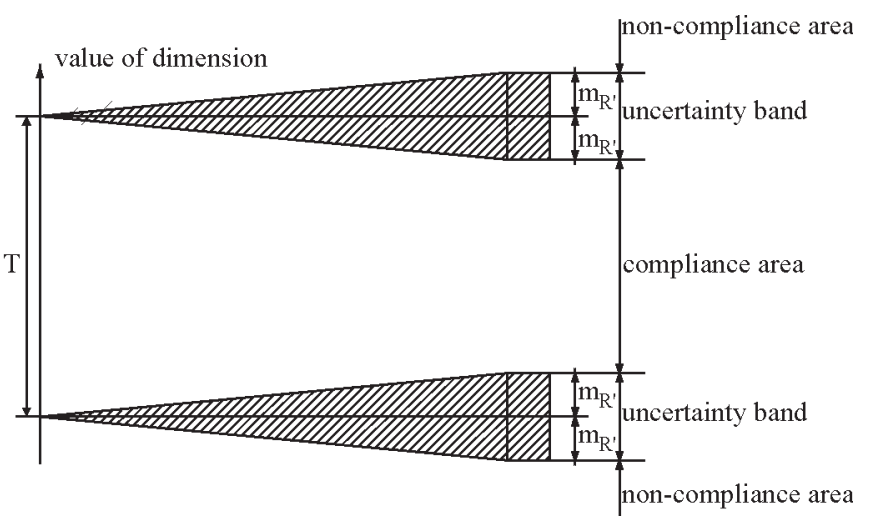

Fig. 8. Influence of measurement uncertainty on assessment of obtained results, where: $\boldsymbol{m}_{\boldsymbol{R}}$,-standard deviation of determination of $R$-dimension; $\boldsymbol{T}$-manufacturing tolerance, compliance area-tolerance area lessened by standard deviation of determination of $R$-dimension; non-compliance area - areas outside the tolerance area increased by standard deviation of measurement; uncertainty band - the interval within which neither compliance nor non-compliance can be stated

\section{EXAMPLE MODELLING PROCESS}

To better highlight the described processes and their possible applications an example of modelling process based on a real measurement task is presented below.

In the given example the modelling equation was subjected also to maximization process that showed a scale of possible profits available due to optimizing process.

The four phases can be distinguished in the modelling process in question:

$1^{\text {st }}$ phase: Determination of input parameters (measurement method, measuring instrument, available coordinates of base points, admissible location of measuring instrument, manufacturing tolerance of an object to be measured);

$2^{\text {nd }}$ phase: Determination of optimum location of measuring instrument and base points [acc.Eqs (15) (17) (18)];

$3^{\text {rd }}$ phase: Calculation of standard deviation of ,z" - coordinates of measurement points [acc. Eq.(12)];

$4^{\text {th }}$ phase: Verification.

The designed control \& measurement system is aimed at checking waviness of inner bottom of a bottom section of ship hull during its assembling on slipway The schematic situation diagram of the object to be measured is presented in Fig. 9.

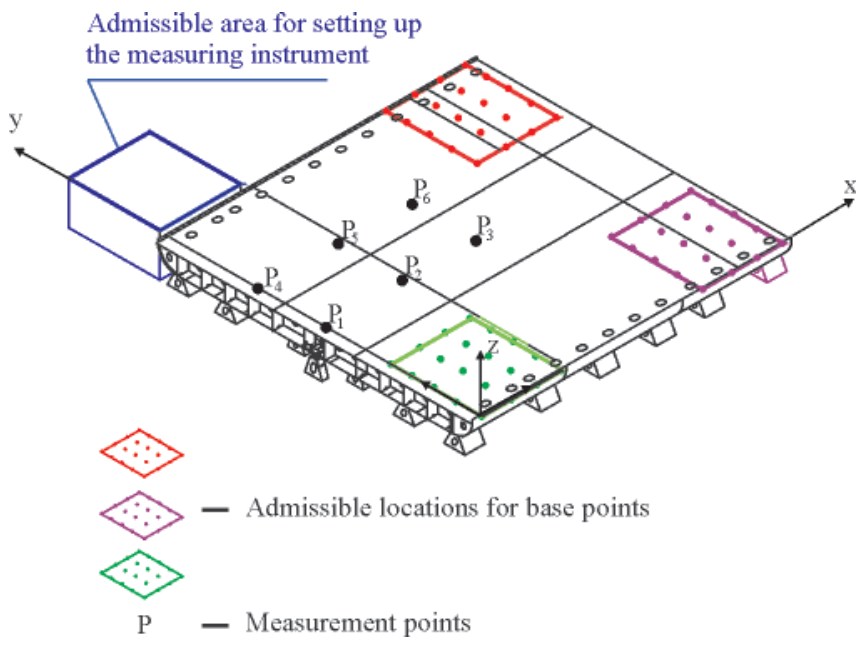

Fig. 9. Schematic situation diagram of the discussed measurement task

As assumed, the measurements were performed with the use of Ni-021A levelling instrument (a relevant value of readout error taken from measuring rod is given in Fig. 7). Tolerances for measured quantities, established by ship design office were equal to $\pm 7 \mathrm{~mm}$.

In order to keep this presentation as clear as possible only final results of particular calculations are attached.

In the case in question the objective function is composed of six components $\mathrm{r}_{\mathrm{z}_{\mathrm{P}_{\mathrm{i}}}}$ :

$$
\mathrm{F}=\mathrm{r}_{\mathrm{z}_{\mathrm{P}}}+\mathrm{r}_{\mathrm{z}_{\mathrm{P}_{2}}}+\mathrm{r}_{\mathrm{z}_{\mathrm{P}_{3}}}+\mathrm{r}_{\mathrm{z}_{\mathrm{P}_{4}}}+\mathrm{r}_{\mathrm{z}_{\mathrm{P}_{5}}}+\mathrm{r}_{\mathrm{z}_{\mathrm{P}_{6}}}
$$

Particular elements of the objective function are described by using Eq. (17). The component $t$ described by means of Eq. (18) took the following form for the investigation results shown in Fig. 7:

$$
\begin{gathered}
\mathrm{t}_{1}=0.0001714\left[\left(\mathrm{x}_{1}-\mathrm{x}_{\mathrm{j}}\right)^{2}+\left(\mathrm{y}_{1}-\mathrm{y}_{\mathrm{j}}\right)^{2}\right]+ \\
+0.0017857 \sqrt{\left(\mathrm{x}_{1}-\mathrm{x}_{\mathrm{j}}\right)^{2}+\left(\mathrm{y}_{1}-\mathrm{y}_{\mathrm{j}}\right)^{2}}+0.3242857
\end{gathered}
$$

The obtained optimization results, i.e. the coordinates of the base points as well as measuring stand, are presented in Fig. 10. Values of the coordinates are given in meters. In Fig. 10 the most unfavourable variant is also given.

a) VARIANT 1 (optimal)

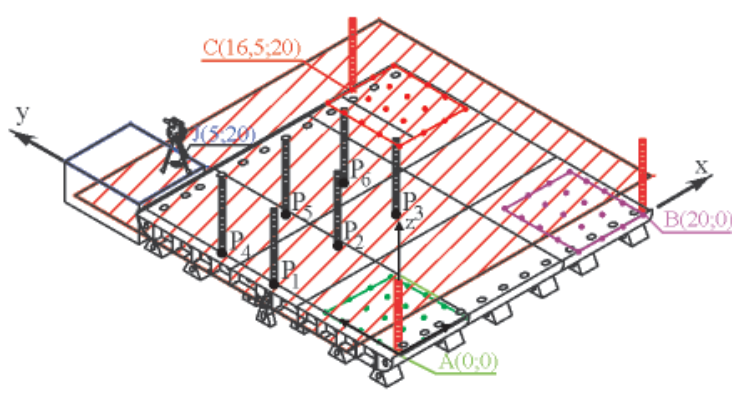

b) VARIANT 2 (most unfavourable)

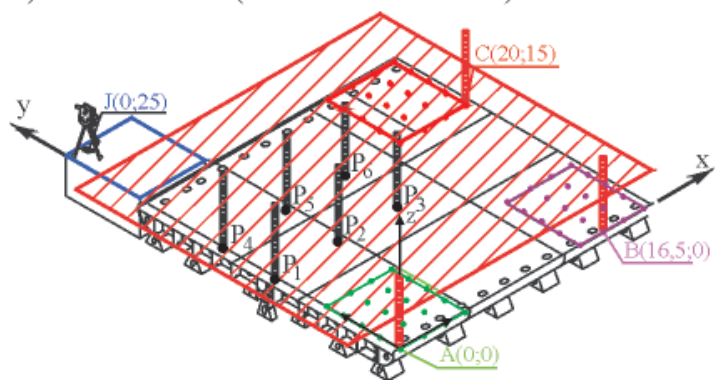

Fig. 10. The optimum variant of the measurements, (a), and the most unfavourable one,(b)

For the parameters presented in the figure was determined standard deviation of , $\mathrm{Z}$ " - coordinate of the points $\mathrm{P}_{1}, \mathrm{P}_{2}, \mathrm{P}_{3}$, $\mathrm{P}_{4}, \mathrm{P}_{5}, \mathrm{P}_{6}$. For the calculations Eqs. (12) were usedThe value of the standard deviation of determination of location coordinates of measuring rods was assumed to be $5 \mathrm{~mm}$. The obtained results are graphically presented in Fig. 11.

Taking into account the value of manufacturing tolerances of the measured object, equal to $\pm 7 \mathrm{~mm}$, one can state that the obtained results of measurement uncertainty satisfy the basic requirements according to the Berndt principle. When after completing the measurements the obtained results are placed within the uncetainty area (see Fig. 8) the measurements should be repeated with changed input parameters. In the case in question the most suitable operation would be to use a measuring instrument of a smaller error of readouts taken from measuring rod.

On the basis of the obtained results it can be stated that this is choice of location of base points and measuring instrument stand which is crucial for accuracy of measurements performed 


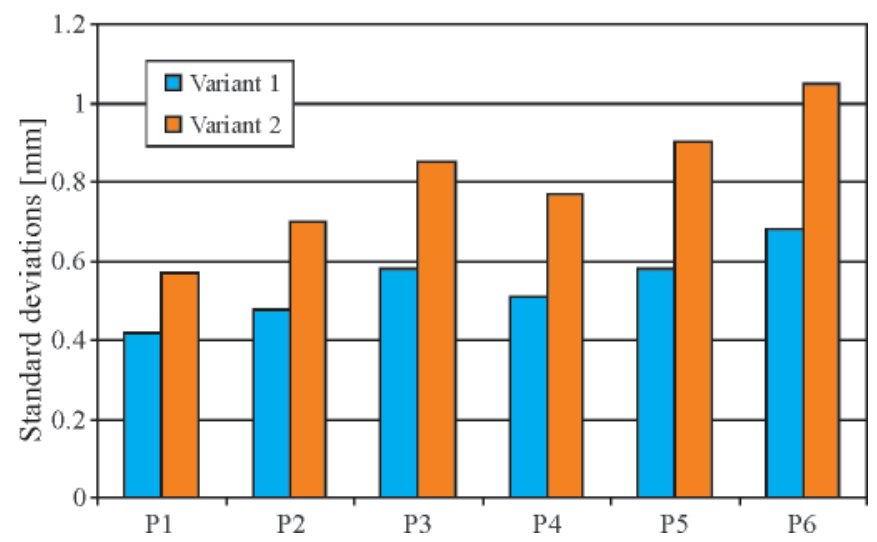

Fig. 11. Values of standard deviation of determination of $z$ "-coordinates of the points $P_{i}$

with the use of the optical levelling method. The results obtained from the above presented calculation process for the most unfavourable variant as well as the optimum one reveal positive consequences of application of optimization methods. The presented case is rather not complex, for more complex measuring processes profits due to application of the discussed methods are greater.

As the presented example confirms, due to the application of modelling process effective control of manufacturing tolerances can be ensured by using optical measuring instruments.

\section{CONCLUSIONS}

- The solutions presented in this paper result from investigations in the area of shipbuilding metrologycarried out for the sake of production enterprises of medium- or low- level technological support. The fact has determined the guidelines as well as limitations which appeared during realization of the task in question. The proposed solutions are mainly addressed to enterprises of the above mentioned kind. In such enterprises permanent dimensional control is essential, that makes role of measurement processes more meaningful and in consequence the discussed problems more important.

- The solutions proposed in this paper are tested by GEOMETR company which carries out measurement operations in the enterprises producing lar ge-size steel structures.

\section{BIBLIOGRAPHY}

1. Fausett, Laurene V.: Numerical methods using MathCAD, Upper Saddle River, Prentice Hall, 2002

2. Humieny Z.; Bialas S.; Osanna P.H.; Tamre M.; Weckenmann A., Blunt L. (et al.): Geometrical Product Specifications (GPS) - course for Technical Universities. Warsaw University of Technology Printing House, Warsaw, 2001

3. Jagielski A.: Geodesy I. Stabill Publishing House, Cracow 2002.

4. Niebylski J.: Optimization of the collection of geometrical data in shipbuilding. The International Conference on Marine Technology ODRA 99, Computational Mechanics Publications, Southampton - Boston, 2000

5. Okumoto Y.: Dimensional Error of Assembled Blocks. Journal of Ship Production, Vol. 17, No. 1, 2001

6. Okumoto Y.: Optimization of Block Erection Using a Genetic Algorithm. Journal of Ship Production, Vol. 18, No. 2, 2002.

7. Rutkowski R.: Geometrical control systems modeling of threedimensional steel structures referring to the required accuracy standards. Doctoral thesis, Szczecin University of Technology, Maritime Technology Faculty, Szczecin, 2005.

\section{CONTACT WITH THE AUTHOR}

Radosław Rutkowski, Ph. D.

West Pomeranian University of Technology, Szczecin

Faculty of Marine Technology

Al. Piastów 41

71-065 Szczecin, POLAND

e-mail: rutex@zut.edu.pl 